\title{
Electroless Plating of NiP and Cu on Polylactic Acid and Polyethylene Terephthalate Glycol-Modified for 3D Printed Flexible Substrates
}

\author{
R. Bernasconi, ${ }^{\mathrm{a}, *}$ G. Natale, ${ }^{\mathrm{b}}$ M. Levi, ${ }^{\mathrm{b}}$ and L. Magagnin ${ }^{\mathrm{a}, * *, \mathrm{z}}$ \\ ${ }^{a}$ Dipartimento di Chimica, Materiali e Ingegneria Chimica "Giulio Natta", Politecnico di Milano, 20131 Milano, Italy \\ ${ }^{b}$ Dipartimento di Chimica, Materiali e Ingegneria Chimica "Giulio Natta", Politecnico di Milano, 20133 Milano, Italy
}

\begin{abstract}
Electroless nickel and copper metallization of 3D printed polymers like polylactic acid and polyethylene terephthalate glycol modified is presented. The plating process is tested on suitable samples, which reproduce the characteristic morphologies used in 3D printing of objects. An alkaline etching is used for both polymers in order to modify the surface properties and to enhance the adhesion and uniformity of the metallic coating. In the case of polylactic acid, a plasma treatment is applied as well to further improve adhesion of the metallic coating. For the activation of the surface, a tin free process involving an immersion in a palladium solution and subsequent reduction to form metallic nuclei is employed. Electrolytes are formulated and selected to operate in temperature ranges comparable with the glass transition temperatures of the polymers. Adherent and uniform layers of $\mathrm{NiP}(3-4 \% \mathrm{P} \mathrm{wt})$ and $\mathrm{Cu}$ can be easily obtained for esthetic and functional applications, also on flexible substrates.

(c) The Author(s) 2016. Published by ECS. This is an open access article distributed under the terms of the Creative Commons Attribution 4.0 License (CC BY, http://creativecommons.org/licenses/by/4.0/), which permits unrestricted reuse of the work in any medium, provided the original work is properly cited. [DOI: 10.1149/2.1201609jes] All rights reserved.
\end{abstract}

Manuscript submitted February 29, 2016; revised manuscript received July 14, 2016. Published July 27, 2016. This was Paper 1141 presented at the Chicago, Illinois, Meeting of the Society, May 24-28, 2015.

Since its introduction in the early $1980 \mathrm{~s},{ }^{1} 3 \mathrm{D}$ printing has acquired a great relevance for research and industry. In the beginning this technique, based on the sequential deposition of layers to obtain three dimensional objects from a virtual model, found application in rapid prototyping and custom made machine parts. ${ }^{2}$ In the last few years however a new industrial revolution began, as home 3D printers can nowadays be easily purchased on the market. This fact is starting to change the common concept of mass production, since 3D printing has the potential to start a new form of handicraft: the customer can obtain the tridimensional model of the desired object and subsequently print it. The production of some goods can thus be moved from factories to homes, with potential advantages. ${ }^{3}$ Other recent applications for $3 \mathrm{D}$ printing have been found in medicine, where the possibility to $3 \mathrm{D}$ print scaffolds, ${ }^{4}$ cell cultures ${ }^{5-7}$ or even organs ${ }^{8}$ has been investigated.

Many 3D printing techniques exist, like stereolitography (SLA), ${ }^{9}$ selective laser sintering (SLS) ${ }^{10}$ or fused deposition modelling (FDM). ${ }^{11}$ Only the latter is however finding the cited commercial success due to the low cost of the materials and the ease of operation. Objects that are complicate or even impossible to manufacture with conventional techniques, can be produced in reduced time ranges with this technique. It is on the other hand expensive to manufacture metallic objects. Some 3D printing techniques are suitable for direct metal processing, like SLS, ${ }^{10}$ while for all the methods it is always possible to print the objects and subsequently cast them in a foundry. These two ways are however difficult to apply if the goal is to keep the process inexpensive and homemade.

Another possibility to achieve a metal finishing for 3D printed object is to metallize only the surface of the polymer used in the process. This makes possible to achieve the desired properties of the metals without performing a real bulk metal 3D printing. ${ }^{12}$ Metallization processes like PVD can always be applied, but metallization based on wet chemistry is generally preferred for the low cost. Among the polymers used in FDM (PET, ABS, PLA, PETG, PE, ... ), some can be easily metallized using electroless plating, a method able to give uniform and thick layers of many metals. ${ }^{13}$ It is however important to notice that the polymers that are easy to be electroless metallized are also difficult to be $3 \mathrm{D}$ printed with good results. These include $\mathrm{PET}^{14}$ and $\mathrm{ABS},{ }^{15}$ while the possible metals for the coatings include $\mathrm{Cu}, \mathrm{NiP}$ and others. ${ }^{16}$ PLA (polylactic acid) and PETG (polyethylene terephthalate glycol modified) are on the contrary easy to print due to the high dimensional stability of the polymer during solidification. A complete

*Electrochemical Society Student Member.

**Electrochemical Society Member

${ }^{\text {zE}}$-mail: luca.magagnin@polimi.it description of a method to electroless plate parts obtained via FDM of these two polymers is not available, even if some attempts to metallize plasma treated PLA substrates are described in literature. ${ }^{17}$

The main aim of the present work is thus to provide a method to electroless metallize 3D printed PLA and PETG. The optimized method is described and the influence of some parameters on the final quality of the metallic layer is discussed. ${ }^{18}$ Adherent and uniform layers of $\mathrm{Cu}$ and low phosphorus $\mathrm{NiP}$ are obtained and subsequent electrodeposition of other metals is investigated. The electroless coatings or the multilayers obtained can be used for esthetic or functional applications. Particular attention is devoted to the plating of flexible substrates obtained by 3D printing, with applications in the field of wearable devices and flexible electronics.

\section{Experimental}

Samples used for the fundamental characterization of the process were printed using TreeD Filaments PLA wire and Colorfabb PETG wire by mean of a Delta 2040 FDM 3D printer by Wasp. The samples measured $1 \mathrm{~cm}$ for $1 \mathrm{~cm}$ and were characterized by an outer structural part extending for $2 \mathrm{~mm}$ from the border. The inner part was printed with a $50 \%$ filling, characterized by a higher distance between the printing tracks. All the chemicals used were purchased from Sigma Aldrich and used as received. The first part of the metallization process was a neutral degreasing, performed in a $50 \mathrm{~g} / \mathrm{l}$ sodium carbonate, $35 \mathrm{~g} / \mathrm{l}$ disodium metasilicate, $3 \mathrm{~g} / \mathrm{l}$ sodium lauryl sulfate solution at room temperature for 2 minute and under sonication. The samples were then rinsed with deionized water. After degreasing, an alkaline etching was done in a $200 \mathrm{~g} / \mathrm{KOH}$ solution for PLA and in a $400 \mathrm{~g} / \mathrm{l}$ $\mathrm{KOH}$ solution for PETG (both at $45^{\circ} \mathrm{C}$ ). After washing the substrates, the activation for electroless plating was achieved immersing the samples in the industrial activator Neoganth 834 (proprietary formulation containing Pd(II) ions supplied by Atotech Gmbh.) for 5 minutes at room temperature first and subsequently in a $20 \mathrm{~g} / \mathrm{l}$ sodium borohydride solution for 1 minute at room temperature. The process was performed 2 times for PLA samples and samples were not washed between the palladium solution and the reducing one. At the end of the activation step the samples were immersed in a $\mathrm{NiP}$ or $\mathrm{Cu}$ electroless solutions. In particular NiP having a $\mathrm{P}$ content between 2 and $3 \%$ was deposited from an alkaline solution containing $32 \mathrm{~g} / \mathrm{l}$ nickel sulfate hexahydrated, $20 \mathrm{~g} / \mathrm{l}$ trisodium citrate, $25 \mathrm{~g} / \mathrm{l}$ ammonium chloride and $28 \mathrm{~g} / \mathrm{l}$ sodium hypophosphite. ${ }^{19}$ The $\mathrm{pH}$ was corrected to 9 using ammonium hydroxide and plating was performed under stirring. In the case of copper, a solution containing $10 \mathrm{~g} / \mathrm{l}$ copper sulfate 
pentahydrated, $22.4 \mathrm{~g} / 1$ TEA, $14.6 \mathrm{~g} / \mathrm{l}$ EDTA and $3.6 \mathrm{~g} / \mathrm{l}$ formaldehyde was employed. The $\mathrm{pH}$ was adjusted to 12.8 with sodium hydroxide and the solution was used at $45^{\circ} \mathrm{C} .{ }^{20}$ Electrodeposition of copper on the NiP metallized sample was accomplished using a pyrophosphate alkaline solution at $\mathrm{pH} 8.5$ and $45^{\circ} \mathrm{C}$ of temperature. For SEM characterization a Zeiss EVO 50 EP was used. Optical microscopy was performed using a Laica DMLM direct illumination microscope. The instrument used for AFM was a NT-MDT SOLVER PRO (in contact mode). Contact angles were measured by mean of a microcamera connected to a PC equipped with a software (Drop Shape Analysis) able to fit the shape of water droplets dispensed by a needle. Adhesion between the polymer and the metal was estimated via a peel test performed using a transparent adhesive tape. After the test, the area of the coating still adherent to the surface was measured. Atmospheric plasma activation was performed using a PECVD System by Kenosistech. After the degreasing step and the subsequent rinsing, 3D printed plates were treated in the plasma chamber in vertical to expose all the surface to the plasma. Then the activation and plating steps followed.

\section{Results and Discussion}

The first part of the experimentation was focused on the development of an optimized method to electroless metallize PLA and PETG. To achieve this, suitable samples were employed. These were characterized by the presence of two zones that reproduced the different morphologies employed in $3 \mathrm{D}$ printing of real objects. The outer part of the samples was constituted of a structural zone having a high density of material and a low porosity. This printing style is used to confer mechanical strength and is typical only of the external parts of the object. For the inner part, like in the samples employed, a filling is added to lower the weight and the cost of the final piece. This part was characterized in the samples by a high porosity and the only difference with respect to the structural part was the distance between the solidified polymeric wires that form the object. The filling is of particular interest when using wet metallization due to its intrinsic porosity, which increases the risk of solution entrapment during the various steps of the process.

Influence of etching time.-After the initial degreasing step, an alkaline etching was applied to the PLA and PETG samples. This method is extensively used to modify the surface of the two polymers $^{21-23}$ and was used in the present work to increase their surface roughness and to modify the surface energy. A proper etching is necessary to provide adhesion between the polymer and the metallic layer on top. This happens thanks to the formation of cavities on the surface (which can mechanically interlock with the metal) or to the chemical modification of the surface itself (in particular an increase in wettability is beneficial for electroless plating). It is thus vital to find the optimal etching time to achieve the best adhesion.

Reaction 1 represents the degradation route occurring in the case of $\mathrm{PLA}^{22}$ when immersed in a solution containing $\mathrm{OH}^{-}$:

$$
\begin{aligned}
& -\mathrm{O}-\mathrm{CO}-\mathrm{O}-\mathrm{C}-\mathrm{CO}-\mathrm{O}-+\mathrm{OH}^{-} \\
& \quad \rightarrow \text {-O-CO-OH + HO-C-CO-O- }
\end{aligned}
$$

When the polymeric chains break new $-\mathrm{OH}$ and $-\mathrm{COOH}$ chemical groups are introduced at the surface, modifying thus contact angle and quality of the final coating. A similar mechanism, involving the breaking of an ester bond, ${ }^{24}$ can be observed in the case of PETG (Reaction 2):

$$
\mathrm{R}_{1}-\mathrm{CO}-\mathrm{O}-\mathrm{R}_{2}+\mathrm{OH}^{-} \rightarrow \mathrm{R}_{1}-\mathrm{CO}-\mathrm{OH}+\mathrm{HO}-\mathrm{R}_{2}
$$

Also for PETG new -OH and - $\mathrm{COOH}$ chemical groups are introduced by the degradation process. This reaction is in general slower than the one occurring for PLA, and for this reason a $400 \mathrm{~g} / \mathrm{l} \mathrm{KOH}$ solution was used instead of a $200 \mathrm{~g} / \mathrm{l} \mathrm{KOH}$. The formed groups are the same for the two polymers and for this reason only their surface density, coupled with the properties of the polymers, determines the surface energy after the treatment.
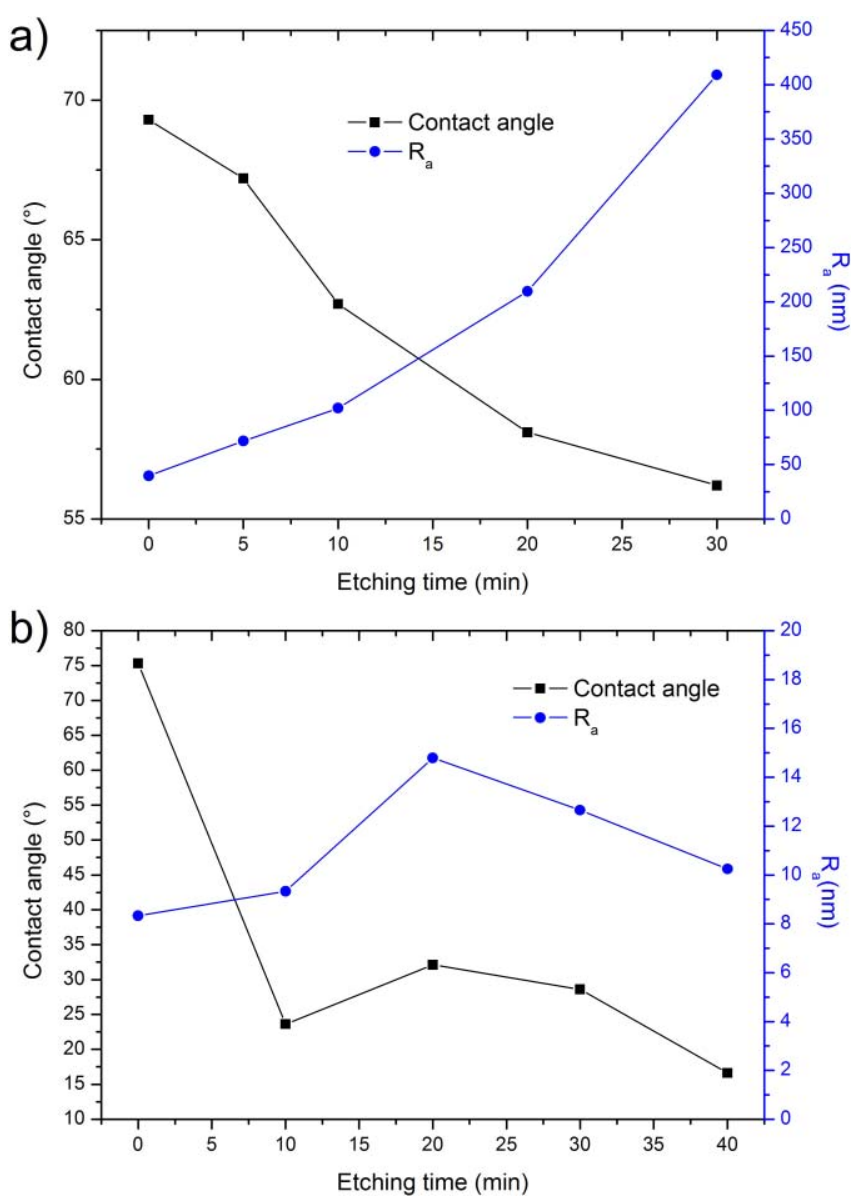

Figure 1. Influence of etching time on contact angle and roughness for PLA (a) and PETG (b).

The effect of different etching times on surface roughness, contact angle and metal adhesion was investigated for PLA and PETG. Figures 1 and 2 depict the variation of these three parameters for the two polymers. NiP was deposited for 14 minutes ( $1 \mu \mathrm{m}$ thickness) to perform the adhesion tests.

From Figure 1a it is evident that increasing etching times had a considerable effect on the surface of PLA. Contact angle decreased up

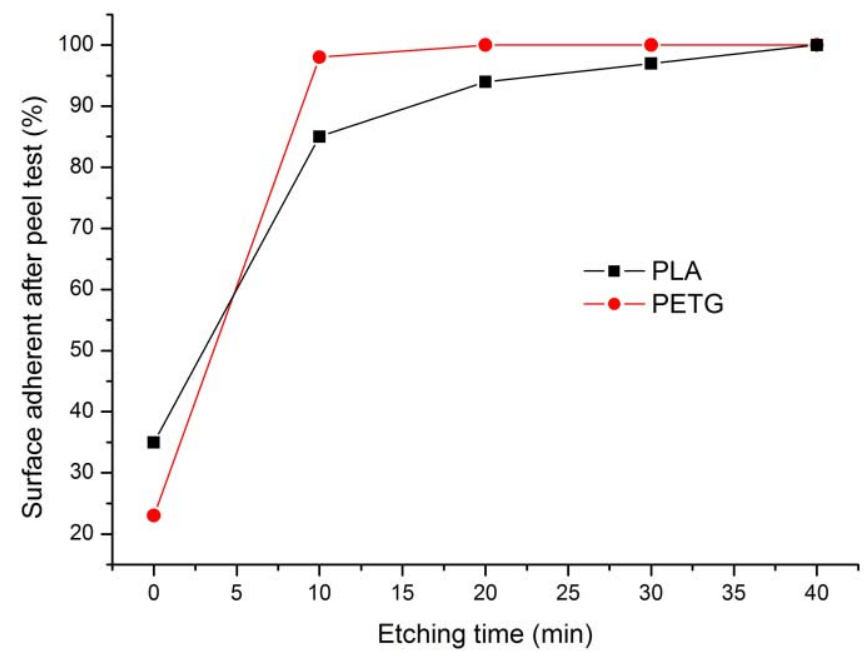

Figure 2. Influence of etching time on adhesion for PLA and PETG (percentage of coating not removed by the peel test). 


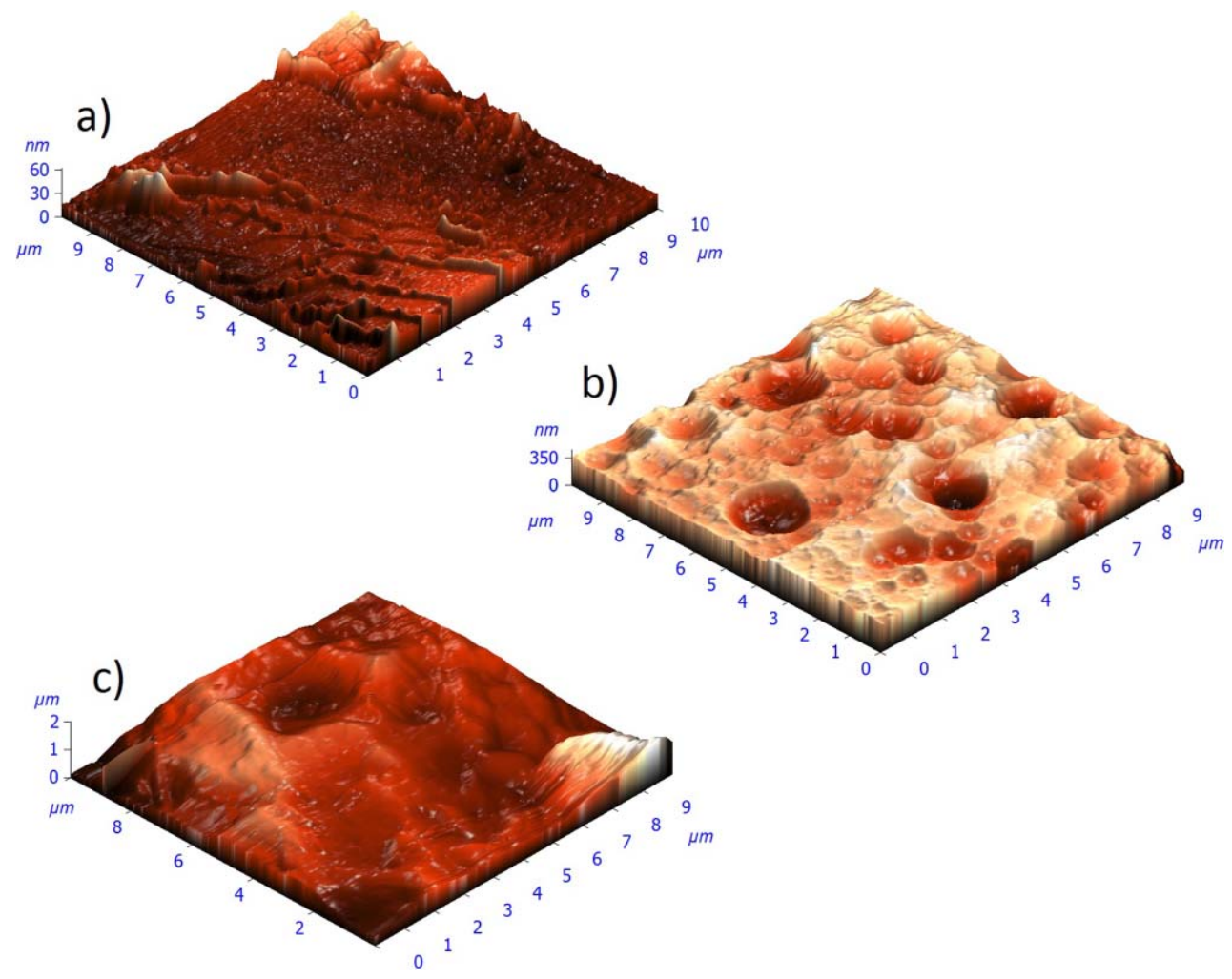

Figure 3. AFM surface profiles for PLA untreated (a), 10 minutes etched (b) and 30 minutes etched (c).

to $57^{\circ}$, as observed in the literature, ${ }^{22}$ while roughness $R_{a}$ increased of one order of magnitude. The combined effect of the variation of these two parameters is evident in Figure 2 on the adhesion of the $\mathrm{NiP}$ coating. Acceptable adhesion was reached for the longest etching time, while in the other cases partial detachment of the layer was always observed.

The roughness increase for PLA can be visualized using AFM. Figure 3 reports the surface profile recorded for three samples at different etching times.

The modification of the surface is evident also from the SEM images acquired using the secondary electrons signal (Figure 4).

The same parameters can be employed to analyze the effect of pretreatment in the case of PETG (Figures $1 b$ and 2). For PETG the surface roughness was not significantly affected by the immersion in $\mathrm{KOH}$, while the contact angle reached very low values. Adhesion was satisfactory also at low etching times. When comparing the PETG case with PLA, it is possible to appreciate the greater influence of surface energy over roughness on the final adhesion of the substrate. PETG became almost superhydrophilic after immersion in $\mathrm{KOH}$, and the NiP adhesion was good even if roughness $\mathrm{R}_{\mathrm{a}}$ was in the order of 10 $\mathrm{nm}$. On the contrary PLA could not reach low enough contact angles with alkaline etching and the only way to achieve suitable adhesion of NiP was to increase roughness. In the case of PLA this was possible because the degradation reaction tends to remove considerable amounts of material from the surface, while in the case of PETG the degradation mainly forms new chemical groups on the surface. This difference in behavior is connected to the chemistry of the two materials: PLA is less resistant to alkaline etching, and thus a real removal of material from the surface coupled with a limited $-\mathrm{COOH} /-\mathrm{OH}$ groups formation takes place. PETG on the contrary is more resistant and the polymeric chains are not completely disaggregated and solubilized, but new chemical groups are formed on the surface due to the ester bonds breaking.

The limited surface damaging of PETG is evidenced also by the SEM image of the surface (Figure $4 \mathrm{~b}$ ), where the creation of superficial nanoporosity can be observed. The AFM analysis, where the actual
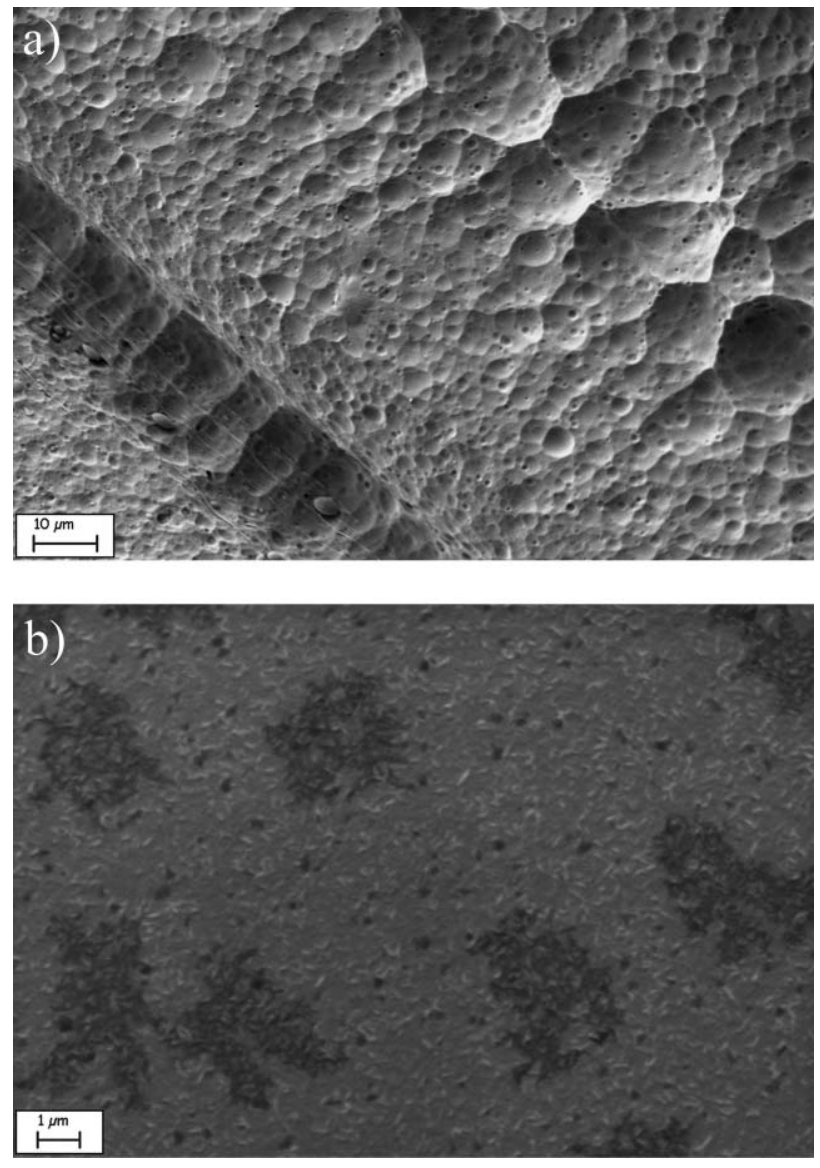

Figure 4. PLA (a, 20 minutes etching) and PETG (b, 40 minutes etching) surface (SEM, secondary electrons). 

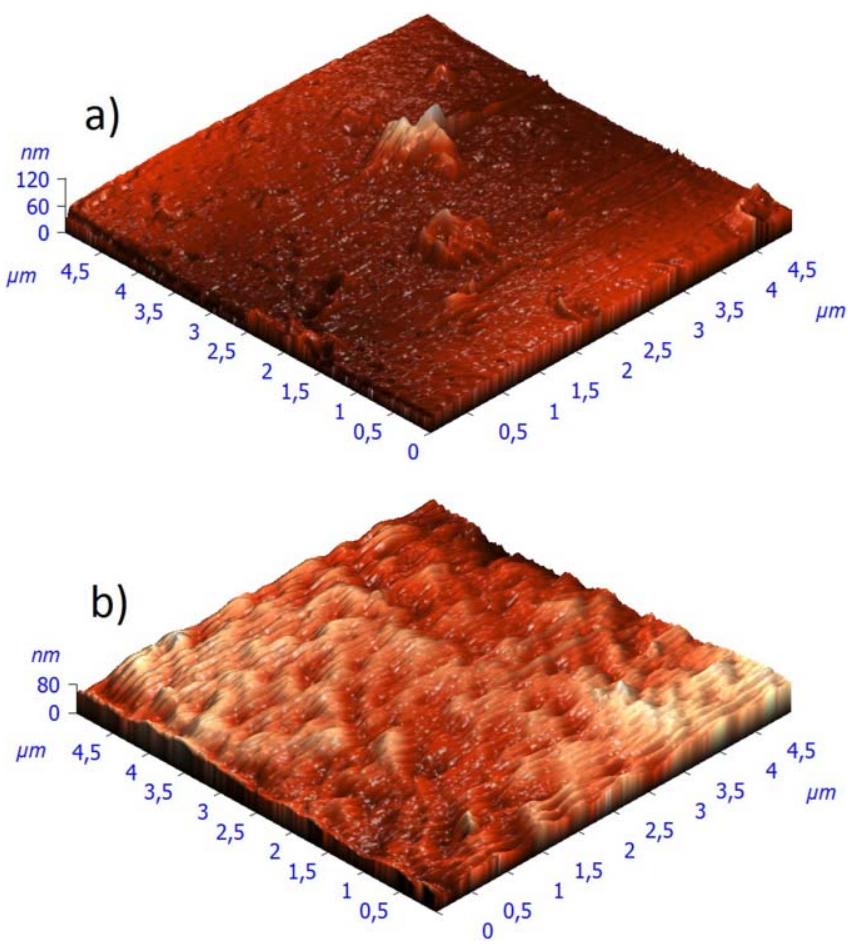

Figure 5. AFM of untreated PETG surface (a) and of PETG after 40 minutes etching in $\mathrm{KOH}$ (b).

dimension of the surface roughness can be better observed, confirmed the SEM observation (Figure 5).

Activation.-Immediately after the etching step, samples were immersed in Neoganth 834 to absorb Pd(II) on the surface and subsequently dipped in the sodium borohydride solution to reduce metallic ions to elemental palladium. As a consequence of the different surface energies, PLA and PETG react differently when activated for electroless plating. The Pd absorption on the polymer surface was nearly immediate, but PLA required the absorption/reducing process to be performed two times to achieve uniform activation. This fact can be correlated with the relatively high contact angle after etching observed in the case of PLA, which probably reduced the quantity of Pd absorbed by the surface. PETG on the other hand guaranteed a good uniformity with one activation cycle as a consequence of the low contact angle after etching. The activation process itself lowered the contact angle of the surface, with both PLA and PETG presenting values decreased by nearly $5^{\circ}$.

The Pd nuclei formed were evidenced on the surface of PETG using SEM. The same analysis was not performed in the case of PLA because the low heat resistance of the polymer made difficult the observation of the surface at the high magnifications needed to observe the nuclei. In the case of PETG treated for 30 minutes in $\mathrm{KOH}$, a particle density of $1.25 \times 10^{4}$ particles $/ \mathrm{mm}^{2}$ was estimated.

$\mathrm{NiP}$ and $\mathrm{Cu}$ plating.-After the activation steps, samples were electroless plated with $\mathrm{NiP}$ or $\mathrm{Cu}$. Figures 6 and 7 depict the SEM analysis of the layers formed on PETG and PLA. The zone of the sample considered for SEM in the case of NiP plating (Figure 6) is the filling, and complete coverage of the surface can be observed up to the second polymer layer below the outer one. Both the samples were immersed in the NiP solution for 14 minutes, obtaining thus around 1 $\mu \mathrm{m}$ of thickness. Etching was performed for 30 minutes.

Similar results were obtained in the case of $\mathrm{Cu}$, as evidenced in Figure 7 (20 minutes of deposition; $1.9 \mu \mathrm{m}$ thickness). For both metals the cross sections of the samples evidenced penetration of the electroless plating up to the second, in some zones third, layer of
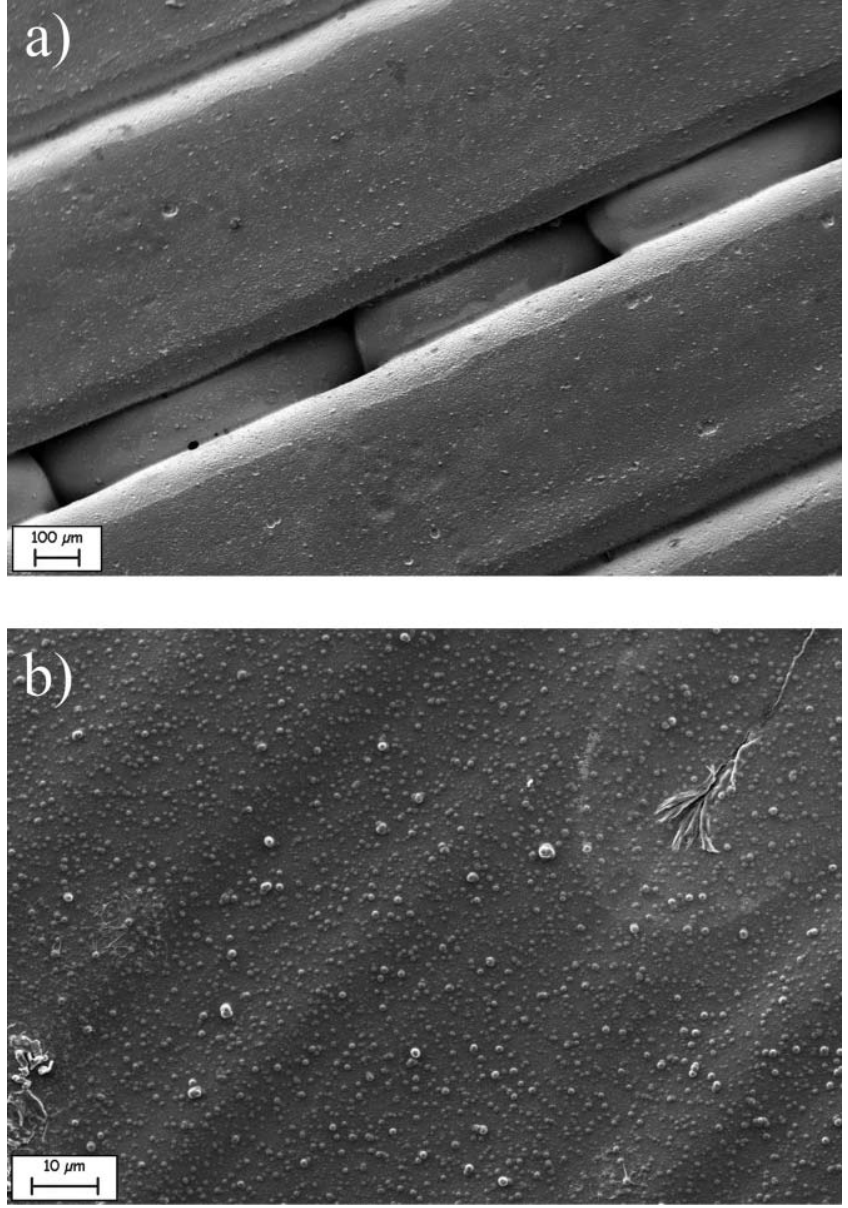

Figure 6. NiP metallized PLA (a) and PETG (b) both after 30 minutes etching in $\mathrm{KOH}$.

polymeric material. This data is strongly dependent on the distance between the printing lines, and thus on the porosity of the filling.

The evolution of surface roughness was evaluated by mean of AFM and results are reported in Table I.

A roughness reduction was observed in the case of PLA when plated with $\mathrm{NiP}$ and $\mathrm{Cu}$, probably due to some limited levelling by the plating solution. In the case of PETG on the contrary, a roughness

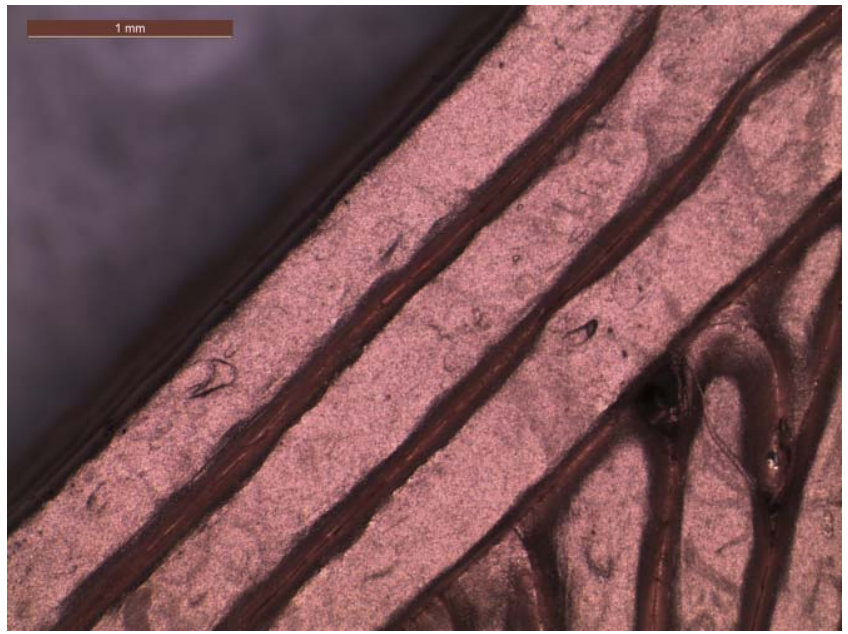

Figure 7. Cu metallized PETG after 30 minutes $\mathrm{KOH}$ etching. 


\begin{tabular}{|c|c|c|c|c|}
\hline Polymer & $\begin{array}{c}\mathrm{R}_{\mathrm{a}} \\
\text { (untreated) }\end{array}$ & $\begin{array}{c}\mathrm{R}_{\mathrm{a}} \\
\text { (etched) }\end{array}$ & $\begin{array}{c}\mathrm{R}_{\mathrm{a}} \\
(\text { etched }+\mathrm{NiP})\end{array}$ & $\underset{\text { (etched }+\mathrm{Cu}}{\mathrm{R}_{\mathrm{a}}}$ \\
\hline PLA & 39.68 & 261.09 & 185.71 & 216.31 \\
\hline PETG & 8.33 & 10.25 & 43.53 & 51.22 \\
\hline
\end{tabular}

increase was observed and this is due to the metallic nuclei at the surface, which present a dimension considerably larger than the minimum feature size on the surface of PETG both treated and untreated.

Plating of flexible samples.-Thin flexible samples were printed using the two polymers and metallized. As for the rigid samples, the metallic layers obtained were characterized by a good adhesion to both the polymers, with good resistance to delamination when subjected to peel test. Only PETG however was able to achieve adhesion values high enough for the plating of flexible substrates (Figure 8). The sample depicted in Figure 8 was etched for 30 minutes in $\mathrm{KOH}$, activated and plated for 14 minutes in NiP solution to obtain $1 \mu \mathrm{m}$ of coating thickness. A severe repeated bending of the sample at a radius of around $5 \mathrm{~cm}$ didn't cause any delamination of the NiP layer. The metallic layer was found to be conductive before and after the test.

In the case of PLA, minor delamination of the layer was noticed in correspondence of the zones characterized by a higher stress. This effect is related to the severe testing conditions used, which are not comparable with the standard peeling test performed on the rigid samples employed for the characterization.

Influence of plasma treatment.-Due to the partial delamination observed, some PLA samples were treated with atmospheric DC plasma at different times and powers. DC plasma operated in oxygen or nitrogen is a widely used technique to modify the surface of polymers like polyimides and PET, ${ }^{25}$ and it has been used in the past also in the case of injection molded PLA. ${ }^{17}$

Two demonstrators like the one presented in Figure 8 and two square samples were treated at $50 \mathrm{~W}$ and $100 \mathrm{~W}$ for 5 minutes. The demonstrators were plated with NiP, while the square samples were used for AFM characterization. AFM analysis showed the formation of a nanometric roughness on the surface (Figure 9).

The morphology observed on the surface presents notable analogies with some of the ones observed by Moraczewsky et al. in the case of injection molded PLA. ${ }^{17}$ Contact angle decreased to roughly $14^{\circ}$ after the application of the treatment at $50 \mathrm{~W}$, and to $10^{\circ}$ after the 100 $\mathrm{W}$ treatment. The surface of the demonstrators was completely covered with a uniform NiP layer after immersion in the plating solution.

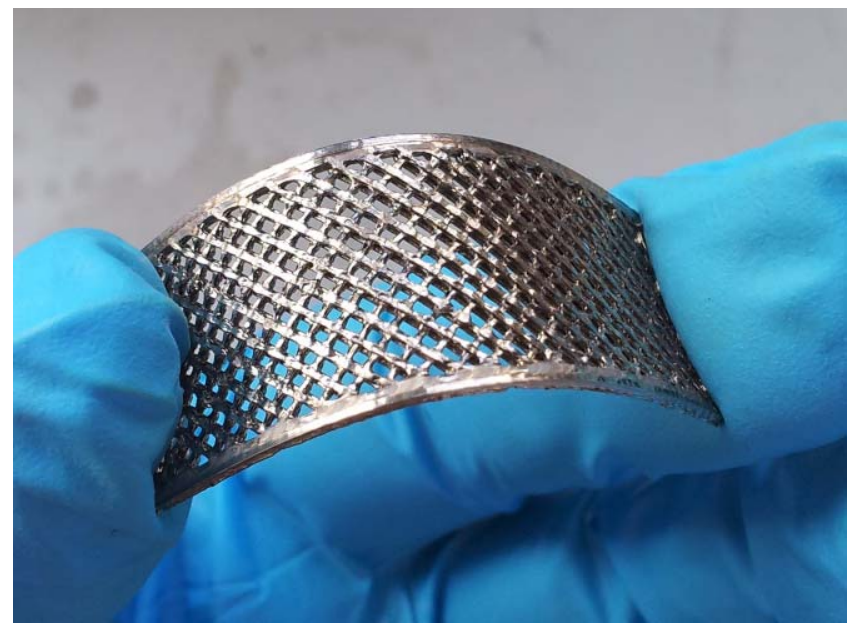

Figure 8. NiP plated PETG flexible demonstrator.

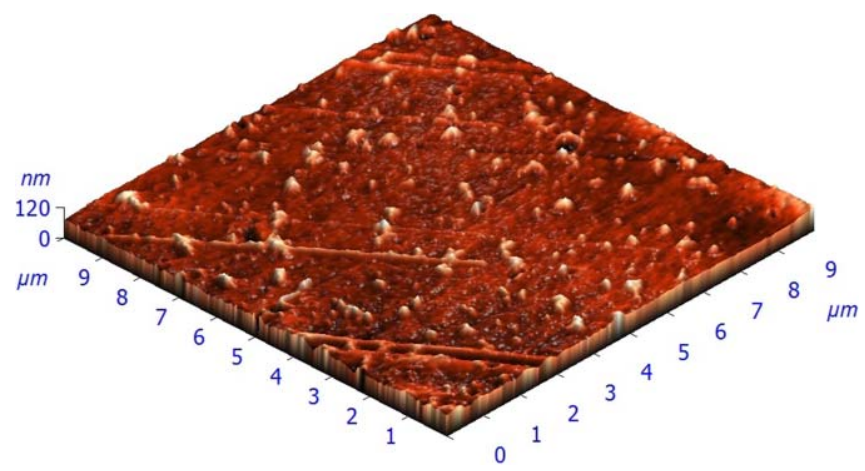

Figure 9. AFM of a PLA sample treated with atmospheric plasma at $100 \mathrm{~W}$ for $300 \mathrm{~s}$.

In the case of the samples treated at $50 \mathrm{~W}$, adhesion was found to be good but the bending of the samples at a radius of about $5 \mathrm{~cm}$ caused the partial delamination of the NiP. Also in the case of the $100 \mathrm{~W}$ treated samples adhesion was found to be good, with no delamination after bending in this case; sample was found to be conductive before and after the bending. Since no chemical roughening was performed on the surface, final roughness of the coating is lower with respect to the result obtained performing the $\mathrm{KOH}$ treatment. In particular a roughness of about $57.23 \mathrm{~nm}$ was observed.

Multilayers electrodeposition.-To conclude the characterization, electrodeposition of multilayers was investigated once the polymeric samples were made conductive by the first electroless deposited NiP or $\mathrm{Cu}$ layer. As an example, $\mathrm{Cu}$ was deposited on a $1 \mu \mathrm{m}$ NiP layer deposited on a PETG demonstrator. An alkaline pyrophosphate solution was employed to deposit around $10 \mu \mathrm{m}$ of pure copper at 20 $\mathrm{mA} / \mathrm{cm}^{2}$. The result obtained is shown in Figure 10.

Similar results were obtained in the case of PLA. On the copper layer obtained in the way described in the text is possible to electrodeposit a wide range of metals, making possible a multiplicity of possible decorative and functional applications for the $3 \mathrm{D}$ printed and metallized objects.

\section{Conclusions}

Electroless NiP and $\mathrm{Cu}$ metallization of both PLA and PETG was achieved applying to the two polymers an optimized all-wet pretreatment and a plating step in two alkaline solutions. Coatings were characterized by good adhesion to the substrate; only in the case of PETG adhesion was enough to avoid partial delamination on flexible substrates. Adhesion on PLA was demonstrated to be high enough

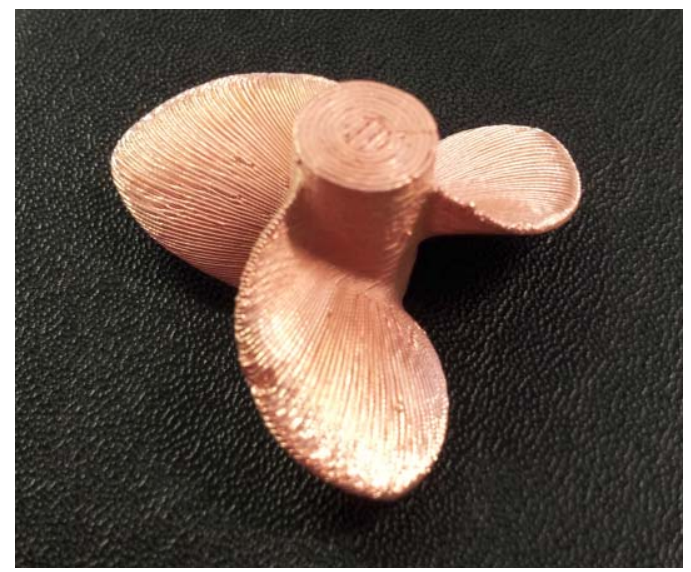

Figure 10. A Cu/NiP plated PETG demonstrator. 
to pass a bending test only after the application of an atmospheric plasma treatment to the pristine PLA surface. Multilayer production was demonstrated testing the possibility of electrodepositing $\mathrm{Cu}$ on a base NiP layer. Results obtained evidence possible applications of the 3D printed and electroless metallized objects in decorative and functional applications. The first may include homeware production or architectonic parts manufacturing as examples, while the latter may include conductive parts for instruments or functional microstructures. In particular, applications in the field of 3D printed flexible electronic substrates can be realistically considered after the analysis of the results obtained from the flexible demonstrators produced applying electroless $\mathrm{NiP}$ and $\mathrm{Cu}$ plating processes.

\section{Acknowledgments}

The authors acknowledge the support of the MEMS\&3D Lab at Politecnico di Milano for the present work.

\section{References}

1. I. Gibson, D. W. Rosen, and B. Stucker, Additive Manufacturing Technologies, Springer, New York (2010)

2. D. T. Pham and S. S. Dimov, Rapid Manufacturing, Springer-Verlag, London (2001).

3. A third industrial revolution, The Economist, 21 April 2012.

4. S. J. Hollister, Nat. Mater., 4, 518 (2005).

5. J. S. Miller, K. R. Stevens, and M. R. Yang, Nat. Mater, 11, 768 (2012)
6. B. Leukers, H. Gulkan, and S. H. Irsen, J. Mater. Sci. Makter. Med., 16, 1121 (2005).

7. D. A. Zopf, S. J. Hollister, and M. E. Nelson, N. Engl. J. Med., 368, 2043 (2013).

8. A. Atala, F. K. Kasper, and A. G. Mikos, Sci. Transl. Med., 4, 160 (2012).

9. P. J. Bártolo (Ed.), Stereolithography: Materials, Processes and Applications, Springer, New York (2011).

10. M. Shellabear and O. Nyrhilä, DMLS - Development History and State of The Art, in LANE 2004 conference, Erlangen, Germany, Sept. 21 (2004).

11. R. Anitha, S. Arunachalam, and P. Radhakrishnana, J. Mat. Proc. Tech., 118, 385 (2001).

12. K. L. Mittal, Metallized Plastics Fundamental and Applied Aspects, VSP BV, Utrech (2001).

13. J. J. Kuzmik, G. O. Mallory, and J. B. Hajdu, Electroless Plating: Fundamentals and Applications, The American Electroplaters and Surface Finishers Society, Orlando (1990).

14. S. Domenech, E. Lima, V. Drago, J. Lima, N. G. Borges, A. Avila, and V. Soldi, J. Appl. Surf. Sci., 220, 238 (2003).

15. A. Equbal and A. K. Sood, Coatings, 4, 574 (2014).

16. M. C. Zhang, E. T. Kang, K. G. Neoh, and K. L. Tan, J. Electrochem. Soc., 148, 71 (2001).

17. K. Moraczewski, P. Rytlewski, R. Malinowski, A. Tracz, and M. Zenkiewicz, Mat. Chem. Phys., 153, 135 (2015).

18. R. Bernasconi, G. Natale, M. Levi, M. Tironi, and L. Magagnin, ECS Trans., 66, 23 (2015).

19. H. Zhang, L. Shen, and J. Chang, J. Ind. Text., 41, 25 (2011).

20. J. Li and P. A. Kohl, Plat. Surf. Fin., 91, 40 (2004).

21. R. M. Rasal, A. V. Janorkar, and D. E. Hirt, Prog. Polym. Sci., 35, 338 (2010).

22. T. I. Croll, A. J. O'Connor, G. W. Stevens, and J. J. Cooper-White, Biomacromolecules, 5, 463 (2004).

23. A. Khoddami, Z. M. Sebdani, and S. Mallakpour, J. Text. Polym., 1, 36 (2013).

24. H. E. M. Saleh (Ed.), Polyester, chapter 4, InTech Open, Rijeka (2012).

25. K. Phasoksom, W. Prissanaroon-Ouajai, N. Brack, and P. Prigam, Adv. Mat. Res., 802, 262 (2013) 